\begin{tabular}{|c|c|c|}
\hline 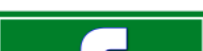 & Int.J.Curr.Microbiol.App.Sci (2021) 10(08): 341-350 & \\
\hline & $\begin{array}{l}\text { International Journal of Current Microbiology and Applied Sciences } \\
\text { ISSN: 2319-7706 Volume } 10 \text { Number } 08 \text { (2021) } \\
\text { Journal homepage: http://www.ijcmas.com }\end{array}$ & 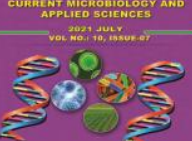 \\
\hline $\begin{array}{l}\text { EXCELLENT } \\
\text { PUBLISHERS }\end{array}$ & & \\
\hline
\end{tabular}

\title{
Evaluation of HiCrome Candida Differential Agar for Identification of Candida Isolated from Various Clinical Specimens
}

\author{
Kirti Nirmal $^{1 *}$, Swati Nirmal ${ }^{2}$, Rohit Chawla ${ }^{2}$ and C. P. Baveja ${ }^{2}$ \\ ${ }^{1}$ Department of Microbiology, University College of Medical Sciences and Guru Tag \\ Bahadur Hospital, Delhi - 110095, India \\ ${ }^{2}$ Department of Microbiology, Maulana Azad Medical College \& Lok Nayak Hospital, \\ New Delhi - 110002, India \\ *Corresponding author
}

\begin{tabular}{|c|}
\hline Keywords \\
\hline $\begin{array}{l}\text { Performance } \\
\text { evaluation, } \\
\text { HiCrome® Candida } \\
\text { Differential Agar }\end{array}$ \\
\hline Article Info \\
\hline $\begin{array}{l}\text { Accepted: } \\
20 \text { July } 2021 \\
\text { Available Online: } \\
10 \text { August } 2021\end{array}$ \\
\hline
\end{tabular}

A B S T R A C T

Speciation of Candida isolates from clinical specimens has become increasingly important due to varied antifungal susceptibility profiles of different species. The conventional methods for identification are time consuming and difficult to perform, while the automated methods are expensive. Identification of yeast by using chromogenic medium is an inexpensive, rapid and an easy to perform method. In the present study the performance of HiCrome ${ }^{\circledR}$ Candida Differential Agar for identification of common Candida species isolated from various clinical samples was compared with VITEK-2 Compact. A total of 50 consecutive clinical isolates of Candida spp. during the period from April 2017 to December 2017, were included in the study. Confirmed identification all isolates was performed using VITEK-2 Compact (Version 8.01). For presumptive identification of Candida spp., all the isolates were inoculated on HiCrome ${ }^{\circledR}$ Candida Differential Agar and incubated at $37^{\circ} \mathrm{C}$ for 48 hours. On the basis of coloration and colony morphology, the isolates were identified at C. albicans, C. krusei, C. tropicalis and C. glabrata. VITEK-2 Compact identified 21 (42\%), 15 (30\%), 9 (18\%), 2 (4\%) isolates as C.albicans, C.tropicalis, C.glabrata and C.krusei, respectively. Of the 21 isolates of $C$. albicans, HiCrome ${ }^{\circledR}$ Candida Differential Agar correctly identified $16(76 \%)$, while $11(73 \%)$ isolates of $C$. tropicalis were correctly identified. All isolates of C.glabrata and C.krusei were correctly identified by the chromogenic medium. Overall the $38(80.1 \%)$ isolates of Candida spp. were correctly identified by the chromogenic medium when compared to the gold standard. HiCrome ${ }^{\circledR}$ Candida Differential Agar performed reasonably well in comparison to Vitek 2 Compact, and may prove to be a useful method for presumptive identification of Candida spp. in laboratories with limited resources. 


\section{Introduction}

Candida species are the most common cause of fungal infections worldwide. They can cause a great variety of infections, including simple, mucocutaneous processes, but they also provoke severe, invasive infections that can involve virtually any organ. (1) Candida species is the members of the normal flora of the skin, mucous membranes, and gastrointestinal tract. They are endogenous opportunists which cause secondary infection in individuals with some underlying immunocompromised conditions. (2, 3) Candidiasis is a common fungal disease found in humans affecting mucosa, skin, nails and internal organs of the body. (4) Candida albicans is generally considered the major pathogen among the Candida species. An increase in the prevalence of non-albicans species has been noted during the last decades. $(5,6)$ There is growing evidence of the increasing use of azoles causing this epidemiological shift. Characterization to species level helps to identify those strains which might be intrinsically resistant to some of the antifungal agents. $(7,8)$ Due to variable clinical presentation of Candida infections, it becomes very important to identify these pathogens from all the clinical specimens. $C$. krusei and $C$. glabrata are known for their innate resistance to fluconazole. The genus Candida includes several species implicated in human pathology such as $C$. albicans, $C$. tropicalis, $C$. parapsilosis, $C$. glabrata, $C$. krusei, C. lusitaniae, $C$. kefyr, $C$. guilliermondii and C. dubliniensis. ${ }^{15}$

Automation in yeast identification methods has been increasingly employed $[10,11]$. Full identification of yeast may take up to $72 \mathrm{~h}$ or more for primary isolation of the organism. Speciation of Candida isolates is conventionally done by germ tube test, sugar assimilation and sugar fermentation tests. Newer methods include CHROM agar, API systems, Vitek 2 YST system and molecular methods. $(9,10)$ Germ tube test is a rapid method to differentiate $C$. albicans and $C$. dubliniensis from other Candida spp. For further speciation chlamydospore formation test, sugar fermentation test and sugar assimilation test can be done. But these tests are time consuming and labour intensive.

Recently, the incidence of life-threatening fungal infections has been the rise, and rapid identification of pathogenic yeasts and detection of polyfungal infections has become mandatory. The most widely used medium for the isolation of Candida species and other fungi is Sabouraud's dextrose agar.

As the identification of yeasts may take several days, employing chromogenic media can help to reduce the time of isolation and identification as well as the detection of mixed cultures by 48-72 hours. ${ }^{11}$ Among the newer tests, CHROM agar and Vitek 2 YST system is rapid and cost effective as compared to other expensive systems like API systems, MALDI-TOF and molecular methods. The time to identification by the VITEK2 YST ID system was 18 hours, compared to 48 to 72 hours by the HiCrome ${ }^{\circledR}$ Candida Differential Agar [15]. In this study, we aimed to compare the HiCrome ${ }^{\circledR}$ Candida Differential Agar and VITEK2 for the identification of Candida strains isolated from different clinical samples. We also had find out the antifungal drug susceptibility by VITEK 2 YST compact system. Such identification gives us prognostic \& therapeutic significance, allowing in the selection of appropriate antifungal agents by clinicians and to prevent the emergence of drug resistance.

\section{Materials and Methods}

The present study was laboratory based carried on clinical isolates of Candida species. Department of Microbiology, Maulana Azad 
Medical College and associated hospital, New Delhi after approval by institutional Ethical Committee (IEC). It was 6 months study from July 2019 to Dec 2019. A total of 50 consecutive Candida isolates from various clinical specimens like high vaginal swab, urine, blood, sputum, pus, bronchoalveolar levage catheter tip, ear swab from patients with candidiasis and stool swab from dental hospital were included in the study.

\section{Isolation and identification of Candida species}

All the clinical samples were screened for budding yeast like cells by direct microscopy of wet mount, gram stain, $10 \% \mathrm{KOH}$ preparation and Gram stain of a colony on routine culture media. All the Candida isolates were subcultured on Sabouraud's Dextrose Agar with Chloramphenicol and incubated at $25^{\circ} \mathrm{C}$ and $37^{\circ} \mathrm{C}$. The Candida isolates were further speciated by standard protocol that include germ tube test, chlamydospore formation on corn meal agar, sugar fermentation and sugar assimilation test. ${ }^{12,13}$ Simultaneously the Candida species were inoculated on HiCrome Candida differential agar and incubated at $37^{\circ} \mathrm{c}$ for 24 to 48 hours and the species were identified by type and colour of the colonies on Hicrome Candida differential agar media as per manufacturer's instruction. ${ }^{14}$

\section{Colony morphology of Candida species on HiCrome Candida differential agar}

Candida albicans: light green coloured smooth colonies

Candida tropicalis: blue to metallic blue coloured raised colonies

Candida glabrata: cream to white smooth colonies
Candida krusei: purple fuzzy colonies

We used ATCC strains of Candida albicans ATCC 10231, Candida glabrata ATCC 15126, Candida krusei ATCC 14243 and Candida tropicalis ATCC 750 as control.

\section{VITEK 2 compact system}

All the Candida isolates was performed by using VITEK-2 Compact System (Version 8.01). The VITEK 2 cards containing serial twofold dilutions of amphotericin B (concentration range, 0.25 to $16 \mu \mathrm{g} / \mathrm{ml}$ ), flucytosine (concentration range, 1 to 64 $\mu \mathrm{g} / \mathrm{ml}$ ), and voriconazole (concentration range, 0.125 to $8 \mu \mathrm{g} / \mathrm{ml}$ ) caspofungin (concentration range, 0.25 to $4 \mu \mathrm{g} / \mathrm{ml}$ ), micafungin (concentration range, 0.25 to 2 $\mu \mathrm{g} / \mathrm{ml}$ ) and fluconazol (concentration range, 2 to $32 \mu \mathrm{g} / \mathrm{ml}$ ) were provided by the manufacturer. The VITEK 2 cards were shipped in sealed packages and were stored at 2 to $8^{\circ} \mathrm{C}$ until testing was performed. It is considering as a gold standard method for candida isolates.

\section{Inoculum preparation}

Stock Inoculum suspensions of the Candida spp. were obtained from 24-h cultures on Sabouraud dextrose agar at $35^{\circ} \mathrm{C}$. Inoculum suspensions for the VITEK 2 system were prepared in sterile saline to turbidity equal to a 2.0 McFarland standard by using the bioMe'rieux DensiChek instrument.

The standardized 2.0 McFarland Inoculum suspension was placed into a VITEK 2 cassette along with a sterile polystyrene test tube and an antifungal susceptibility test card for each organism. The growth was identified by VITEK 2 YST ID -21343 (BioMerieux, India) automated system and also put VITEK 2 AST -07 card (BioMerieux, India) for antifungal drug susceptibility testing. The 
loaded cassettes were then placed into the VITEK 2 instrument; and the respective yeast suspensions were diluted appropriately by the instrument, after which the cards were filled, incubated, and read automatically. The time of incubation varied from 9.1 to $27.1 \mathrm{~h}$, based on the rate of growth in the drug-free control well, and the results were expressed as MICs in $\mu \mathrm{g} / \mathrm{ml}^{7}$

\section{Statistical Analysis}

Data analysis done by using SPSS software version 20. Descriptive statistics such as mean, standard deviation (SD), proportions and graphs were used to describe the data. Differences between proportions were analyzed using chi square test or by Fisher's exact test.

\section{Results and Discussion}

A total of 5 Candida species were isolated from various clinical specimens processed during the study period. Male outnumbered as compared to female (2.5:1). Majority Candida samples were received from Medicine department (60\%) followed by Surgery (13\%), Pediatric (12\%), ENT \& orthopedic (6\%). Dental and Neurosurgery department had minimum Candida samples (4\%). 15-30 years (40\%) were the maximum age group while, more than 75 years age were the lowest (4\%) Age and gender wise distribution of Candida isolates are showing in Table 1.

In present study, sputum was the maximum samples $(42 \%)$ followed by urine sample (12\%) and CSF and BAL samples were the least samples (4\%). Distribution of various species of Candida among various clinical specimens $(\mathrm{N}=50)$. in Figure 1.

Candida albicans was the commonest species isolated 21 (42\%) followed by C. tropicalis 15 (30\%), C. glabrata 9 (12\%), C. krusei 3 (6\%) and C.parapsilosis 2 (4\%). (Figure 2)Isolation rate of non albicans Candida species was higher $29(58 \%)$ as compared to Candida albicans 21 (42\%) (Table 2)

Among the non albicans Candida, Candida tropicalis 15 (30\%) was the commonest followed by C. glabarata 9 (12\%), C. krusei 3 (6\%), and C. parapsilosis 2 (4\%). (Figure 2) These 50 Candida isolates were also subjected to identification using Hicrome Candida differential agar. The results of VITEK 2 compact method and Hicrome Candida differential agar for various species are given in (Table 3).

Of the 21 isolates of $C$. albicans, HiCrome® Candida Differential Agar correctly identified 16 (76\%), while 11 (73\%) isolates of $C$. tropicalis were correctly identified. All isolates of C.glabrata and C.krusei were correctly identified by the chromogenic medium. Overall the $38(80.1 \%)$ isolates of Candida spp. were correctly identified by the chromogenic medium when compared to the gold standard.

There was an agreement in identification by Hicrome Candida differential agar and VITEK 2 compact method for four species. (i.e. Candida albicans, Candida tropicalis, Candida krusei and Candida glabrata). Two Candida isolates (Candida guilliermondii, and Candida kefyr) were not identified by Hicrome candida differential agar. These three Candida species were identified by conventional methods like sugar fermentation and sugar assimilation tests. The colony morphology of Candida albicans, Candida tropicalis, Candida krusei, Candida glabrata and Candida parapsilosis on Hicrome Candida differential agar are shown in Figure 3.

The majority of isolates were susceptible to all antifungal drugs tested by VITEK 2 YST ID - 
21343 for fungus identification and VITEK 2 AST -07 card for antifungal susceptibility testing (BioMerieux, India) Vitek 2 cards compact system demonstrating MIC90 values (the rates of susceptibility to amphotericin B, fluconazole, caspofungin, micafungin and flucocytosine and voriconazole were $97.5 \%$, $87.3 \%, 99.5 \%, \quad 92 \% \quad 86 \%$ and $93.4 \%$ respectively Although some differences were observed among species,

HiCrome ${ }^{\circledR}$ Candida Differential Agar performed reasonably well (80\% concordance) in comparison to Vitek 2 Compact and may prove to be a useful method for presumptive identification of Candida spp., especially in laboratories with limited resources. All Candida isolates were sensitive to Amphotericin B and Flucytosine 62\% isolates of C. albicans and \& $67 \%$ isolates of $C$. glabrata were resistant to echinocandins $4.8 \%$ isolates of $C$. albicans \& $13.3 \%$ isolates of $C$. tropicalis were simultaneously resistant to two classes of antifungals (Azoles \& Echinocandins).(Table 4)

Potential clinical importance of species level identification has been recognized as Candida species differ in the expression of virulence factors and antifungal susceptibility.(4) Candida species also have a direct impact on the choice of empirical antifungal therapy and clinical outcome. Non-albicans candida species are on the rise due to increasing immunocompromised condition. The identification of clinically encountered yeasts by using conventional methods is timeconsuming, labor-intensive, and expensive. ${ }^{16}$ Commercial automated identification systems have been developed, are currently on the market, and are in use in clinical microbiology laboratories. These systems allow for accurate and more rapid identification of medically relevant bacteria and yeasts, improving the quality and cost effectiveness of patient care
16, 17, 18 The VITEK 2 system has been shown to be a reliable fully automated instrument for the identification of microorganisms, including yeasts using the ID-YST cards. Rapid identification of yeast species are very difficult in resource-limited poor laboratories due to lack of trainings, proper reagents and equipments. The conventional methods like inoculation on corn-meal agar, biochemical assimilation and fermentation tests are not used in these laboratories due to lack of resources, expertise and time required for these tests which increase the cost of mycology cultures. Therefore, these laboratories do not go beyond the germ tube test and limit their diagnosis to C. albicans or non albicans Candida. ${ }^{19}$ As a result of which, selection of appropriate agent for antifungal therapy becomes almost impossible. Without standard diagnostic tools, a safe and effective drug treatment, prevention of resistance to antimicrobial therapy and monitoring of resistance are not possible. So, in these settings there is always a need of a medium which helps in the isolation and identification of the agent at the species level. ${ }^{20}$

It is necessary to evaluate simple, cost effective and rapid method like chromogenic medium to identify Candida to species level. Chromogenic agar is a newer and more rapid method to speciate Candida species. It contains enzymatic substrates that are linked to chromogenic compounds. When a specific enzyme cleaves the substrate, the chromogenic substances produce colour. The action of different enzymes produced by yeast species results in colour variation which is useful for presumptive identification of some yeast. ${ }^{21}$

In the present study, conventional method and Hicrome Candida differential agar were used for identification of Candida isolates from various clinical samples and utility of Hicrome Candida differential agar was noted. 
Table.1 Age and gender wise distribution of Candida isolates

\begin{tabular}{|c|c|c|c|c|c|}
\hline Age groups & $\begin{array}{c}\text { Male } \\
(\mathbf{n = 3 6})\end{array}$ & $\mathbf{\%}$ & $\begin{array}{c}\text { Female } \\
(\mathbf{n}-\mathbf{1 4})\end{array}$ & $\mathbf{\%}$ & $\begin{array}{c}\text { Total } \\
\mathbf{N = 5 0}(\boldsymbol{\%})\end{array}$ \\
\hline Birth-15 years & 4 & 11 & 3 & 2.1 & $7(14)$ \\
\hline $\mathbf{1 5 - 3 0}$ years & 11 & 30 & 9 & 64 & $20(40)$ \\
\hline $\mathbf{3 0 - 4 5}$ years & 6 & 16 & 2 & 14 & $8(16)$ \\
\hline $\mathbf{4 5 - 6 0}$ years & 5 & 13 & 3 & 21 & $8(16)$ \\
\hline $\mathbf{6 0}$-75 years & 3 & 8.3 & 2 & 14 & $5(10)$ \\
\hline$>$ 75 years & 2 & 5.6 & 0 & 0 & $2(4)$ \\
\hline
\end{tabular}

Table.2 Distribution of Candida albicans and Non albicans Candida isolates.

\begin{tabular}{|c|c|c|}
\hline Candida isolates & No of isolates $(\mathbf{N}=\mathbf{5 0})$ & Percentage (\%) \\
\hline Candida albicans & 21 & $42 \%$ \\
\hline Non Candida albicans & 29 & $58 \%$ \\
\hline Total & 50 & $100 \%$ \\
\hline
\end{tabular}

Table.3 Identification of Candida spp. by vitek and HiCrome ${ }^{\circledR}$ Candida Differential Agar

\begin{tabular}{|c|c|c|c|}
\hline Candida spp. & $\begin{array}{c}\text { Vitek } \\
\text { Identification }\end{array}$ & $\begin{array}{c}\text { Hicrome agar } \\
\text { identification }\end{array}$ & $\begin{array}{c}\text { Number of Misidentified } \\
\text { spp.N (\%) }\end{array}$ \\
\hline 1. Candida albicans & 21 & 16 & $4(76 \%)$ \\
\hline 2.Candida tropicalis & 15 & 11 & $4(73 \%)$ \\
\hline 3. Candida glabrata & 9 & 9 & - \\
\hline 4. Candida Krusei & 2 & 2 & - \\
\hline Total & 47 & 38 & $80.8 \%$ \\
\hline
\end{tabular}

Table.4 Antimicrobial susceptibility profile of Candida spp from VITEK 2 compact system

\begin{tabular}{|c|c|c|c|c|c|c|c|}
\hline \multicolumn{2}{|c|}{ Candida spp. } & \multirow{2}{*}{$\begin{array}{c}\begin{array}{c}\text { Flucona } \\
\text { zole } \\
\mathbf{n}(\%)\end{array} \\
18(85)\end{array}$} & \multirow{2}{*}{$\begin{array}{c}\begin{array}{c}\text { Voricona } \\
\text { zole } \\
\mathbf{n}(\%)\end{array} \\
18(85)\end{array}$} & \multirow{2}{*}{$\begin{array}{c}\text { Caspofun } \\
\text { gin } \\
\mathbf{n}(\%) \\
9(42)\end{array}$} & \multirow{2}{*}{$\begin{array}{c}\begin{array}{c}\text { Micafun } \\
\text { gin } \\
\mathbf{n}(\%)\end{array} \\
8(38)\end{array}$} & \multirow{2}{*}{$\begin{array}{c}\text { Amphotr } \\
\text { icin B } \\
\text { n(\%) } \\
21(100)\end{array}$} & \multirow{2}{*}{$\begin{array}{c}\begin{array}{c}\text { Flucocytosine } \\
\mathbf{n}(\%)\end{array} \\
21(100)\end{array}$} \\
\hline Candia & $\mathrm{S}$ & & & & & & \\
\hline $\begin{array}{c}\text { albicans } \\
(\mathrm{n}=21)\end{array}$ & $\mathrm{R}$ & $3(15)$ & $3(15)$ & $12(58)$ & $13(62)$ & $0(0)$ & $0(0)$ \\
\hline Candida & $\mathrm{S}$ & $12(80)$ & $13(86)$ & $11(74)$ & $11(74)$ & $15(100)$ & $15(100)$ \\
\hline $\begin{array}{l}\text { tropicalis } \\
(\mathbf{n}=15)\end{array}$ & $\mathrm{R}$ & $3(20)$ & $2(14)$ & $4(26)$ & $4(26)$ & $0(0)$ & $0(0)$ \\
\hline Candida & $\mathrm{S}$ & $6(67)$ & $6(67)$ & $3(33)$ & $3(33)$ & $9(100)$ & $9(100)$ \\
\hline $\begin{array}{c}\text { glabrata } \\
(\mathbf{n}=9)\end{array}$ & $\mathrm{R}$ & $3(33)$ & $3(33)$ & $6(67)$ & $6(67)$ & $(0)$ & (0) \\
\hline Candida & $\mathrm{S}$ & & (0) & $2(100)$ & $2(100)$ & $2(100)$ & $2(100)$ \\
\hline $\begin{array}{l}\text { krusei } \\
(\mathbf{n}=2)\end{array}$ & $\mathrm{R}$ & $2(100)$ & $2(100)$ & $0(0)$ & $0(0)$ & $0(0)$ & $0(0)$ \\
\hline
\end{tabular}


Fig.1 Distribution of various species of Candida among various clinical specimens $(\mathrm{N}=50)$.

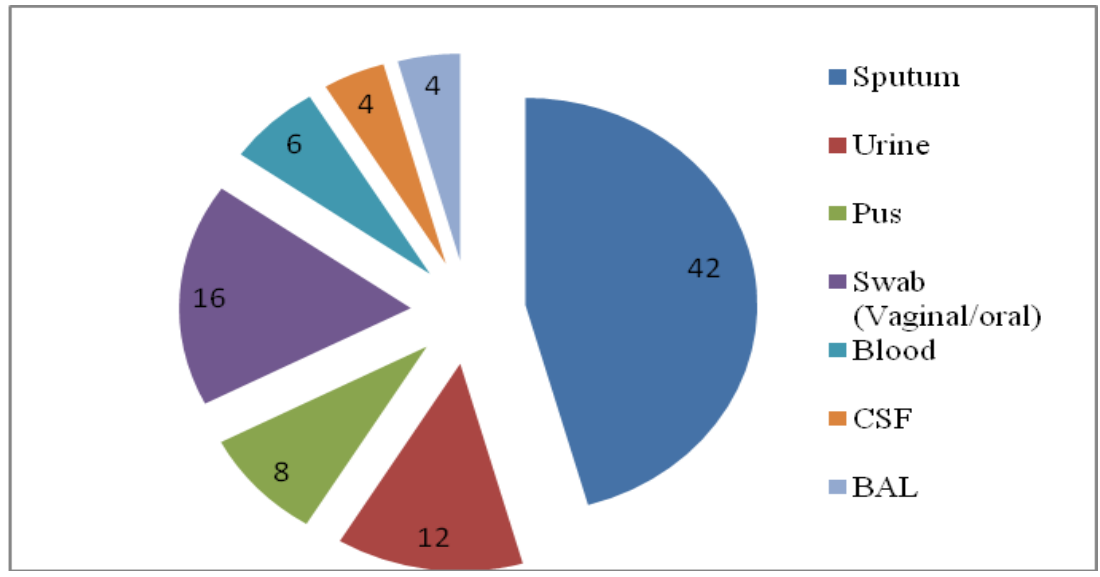

Fig.2 Candida species isolation from various clinical samples $(\mathrm{N}=50)$

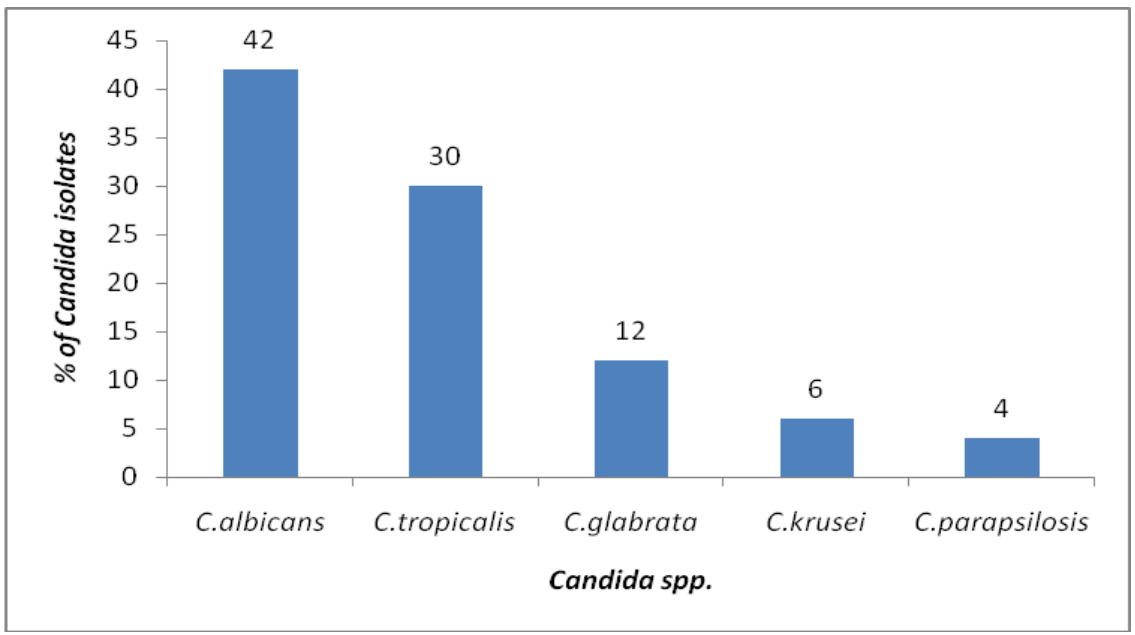

Fig.3 Colony colour of Candida isolates on Hicrome Candida differential agar.

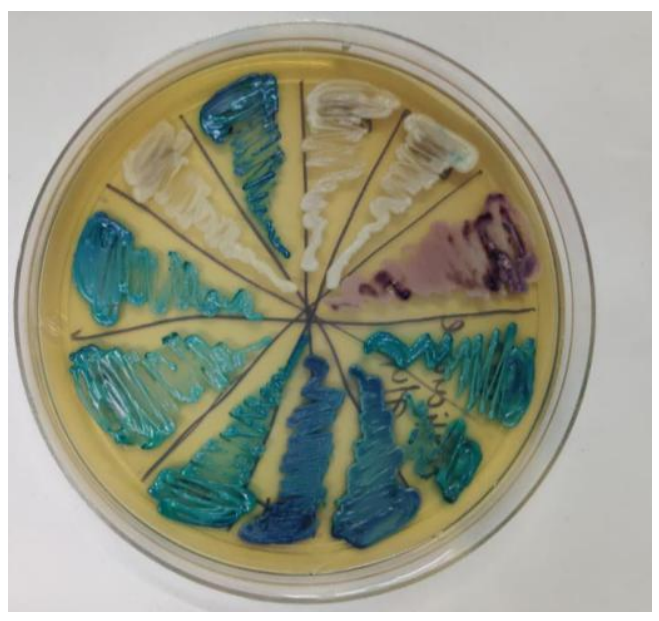


Candida albicans produces light green colonies on Hicrome Candida differential agar. In our study, all the isolates of Candida albicans produced light green colonies on Hicrome Candida differential agar. This is in agreement with other studies from different part of India. 22,23

The Vitek 2 instrument suggested additional biochemical tests to determine more specific identifications. The YST card provided the correct identification for $100 \%$ of the $C$. glabrata isolates, $100 \%$ of the C. krusei isolates, $76 \%$ of C. albicans, and $73 \%$ of $C$. tropicalis.The YST $80.0 \%$ of the Candida isolates were correctly identified, which is comparable to the results reported in prior investigations $(80-90 \%) .{ }^{24,25}$

Tables 4 summarize the in vitro susceptibilities of 50 Candida isolates to fluconazole, voriconazole, caspofungin, micafungin, flucocytosine and amphotericin $\mathrm{B}$, as determined with the Vitek 2 system. Four C. albicans and Cc.tropicalis strain were misidentified in Vitek 2 compact system. Chrome agar rates obtained for C. glabrata, $C$. albicans and other Candida species were $96.3 \%, 95.2 \%$ and $100 \%$, respectively. In this study HiCrome ${ }^{\circledR}$ Candida Differential Agar performed reasonably well ( $80 \%$ concordance) in comparison to Vitek 2 Compact and may prove to be a useful method for presumptive identification of Candida spp., especially in laboratories with limited resources. All Candida isolates were sensitive to Amphotericin B and Flucytosine while, 62\% isolates of C. albicans and \& $67 \%$ isolates of C. glabrata were resistant to echinocandins $4.8 \%$ isolates of C. albicans \& $13.3 \%$ isolates of C. tropicalis were simultaneously resistant to two classes of antifungals (Azoles \& Echinocandins) High frequency of resistance to echinocandins among $C$. albicans \& $\mathrm{C}$. glabrata is a matter of concern. The Vitek 2 YST card is a simple and rapid method for a reliable identification of most clinically important Candida species isolated from blood. More studies are needed to confirm these results.

HiCrome ${ }^{\circledR}$ Candida Differential Agar performed reasonably well in comparison to Vitek 2 Compact, and may prove to be a useful method for presumptive identification of Candida spp. in laboratories with limited resources. HiCrome ${ }^{\circledR}$ Candida Differential Agar showed no major discrepancies in growth potential, colony characters and growth rates for primary isolation from clinical samples as compared to SDA. With few exceptions, the colony colors developed on HiCrome agar were stable and distinct for common Candida species. However, stable color development may take $48 \mathrm{~h}$. We recommend routine use of HiCrome agar in mycology laboratories. Use of this differential media can significantly cut down the turnaround time as well as cost of sample processing.

\section{References}

1. Asmunds Dottir L. R., Erlends Dottir H., Gott Fredsson M. Increasing incidence of Candidemia: Results from a 20 - Year Nationwide study in Iceland. J Clin Microbiol 2002;40:3489-92.

2. Agrawal V, Bhagwat A M, Vishalakshi V, Gode V, Sawant C S: Exploring the potential of chromogenic medium for the identification of medically important yeast species other than candida. Int $J$ Pharm Pharm Sci. 2014, 6(3):291-294.

3. Deorukhkar S C, Saini S, Mathew S. Non-albicans Candida Infection: An Emerging Threat. Interdiscip Perspect Infect Dis. 2014; 2014:615958.

4. Jha B K, Dey S, Tamang M D, Joshy M E, Shivananda P G, Brahmadatan K N: Characterization of candida species isolated from cases of lower respiratory 
tract infection. KUMJ. 2006, 4(3):290294.

5. Shivprakasha S, Radhakrishan K, Karim P M S. Candida spp other than Candida albicans. A major cause of fungemia in a tertiary care centre. Ind J Med Microbiol 2007;25(4):405-407.

6. Mokaddas E M, Al-Sweih N A, Khan Z U. Species distribution and antifungal susceptibility of Candida bloodstream isolates in Kuwait: A 10-year study. J Med Microbiol 2007:56:255-9.

7. Srinivasan L, Kenneth J. Antibiotic susceptibility of Candida isolates in a tertiary care hospital in southern India. Ind J Med Microbiol 2006;24:1:80.

8. Golia S, Reddy K M, Karjigi K S, Hittinahalli V. Speciation of Candida using chromogenic and cornmeal agar with determination of fluconazole sensitivity. Al Ameen J Med Sci 2013;6(2):163-166.

9. Odds F C, Bernaerts R. Chrom agar Candida, a new differential isolation medium for presumptive identification of clinically important Candida spp. J of Clin Microbiol 1994;32(8):1923-9.

10. Jain N, Mathur P, Misra M C, Behera B, Xess I, Sharma S P. Rapid identification of yeast isolates from clinical specimens in critically Ill trauma ICU patients. J Lab Physicians 2012;4(1):30-4.

11. Pinjon E, Sullivan D, Salkin I, Shanley D, Coleman D. "Simple, inexpensive, reliable method foe differentiation of Candida dubliniensis from Candida albicans". J Clin Microbiol 1998;36(7):2093-2095.

12. HiCrome Candida Differential agar. [Online]. [cited 2013 Nov.14.

13. Collee J G, Duguid J P, Fraser A G, Marmion B P. Mackie and McCartney Practical medical microbiology. $13^{\text {th }}$ ed. Hong Kong: Churchill Livingstone; 1989.

14. Chandra J. Text book of medical mycology. 3rd ed. New Delhi: Mehta
Publishers; 2008;266-290.

15. Sulivan, D. J., Westerneng, T. J., Haynes, K A., Bennett, D. E., Coleman, D.C. 1995. phenotypic and molecular characterization of a novel species associated with oral candidosis in HIVinfected individuals. Microbiol., 141: 507-1521.

16. Lin, C. C. S., and D. Y. C. Fung. 1987. Conventional and rapid methods for yeast identification. Crit. Rev. Microbiol. 14:273-288.

17. Quadri, S. M., D. J. Flournoy, S. G. Quadri, and E. G. Ramirez. 1986. Rapid identification of yeasts by semiautomated and conventional methods. Med. Microbiol. Immunol. (Berlin) 175:307-316.

18. Daef E, Moharram A, Eldin S S, Elsherbiny N, Mohammed M. Evaluation of chromogenic media and seminested PCR in the identification of Candida species. Brazilian J Microbiol 2014;45:255-262.

19. Nadeem S G, Hakim S T, Kazmi S U. Use of Chrom agarCandida for the presumptive identification of Candida species directly from clinical specimens in source-limited settings. Libyan J Med 2010,5:2144.

20. Dharmeswari T, Chandrakesan S D, Mudhigeti N, Patricia A, Kanungo R. Use of chromogenic medium for speciation of Candida isolated from clinical specimens. Int J Cur Res Rev 2014;6:1-5.

21. Sivakumar V G, Shankar P, Nalina K, Menon T. Use of Chrom agar in the differentiation of common species of Candida. Mycopathologia 2009;167:4749.

22. Kumar S, Vyas A, Kumar M, Mehra S K. Application of Chrom agar Candida for identification of clinically important Candida species and their antifungal susceptibility pattern. Int J Biol Med Res 2013;4:3600-3606. 
23. Murray, M. P., R. Zinchuk, and D. H. Larone. 2005. Chrom agar Canidida as the sole primary medium for isolation of yeasts and as a source medium for the rapid-assimilation-of-trehalose test. J. Clin. Microbiol. 43:1210-1212.

24. Quadri, S. M., D. J. Flournoy, S. G. Quadri, and E. G. Ramirez. 1986. Rapid identification of yeasts by semiautomated and conventional methods. Med. Microbiol. Immunol. (Berlin) 175:307-316.

25. G. P. Moran, D. J. Sullivan, D. C.
Coleman, Emergence of non-Candida albicans Candida species as pathogens. In: Calderone RA. Candida and Candidiasis (ASM Press, Washington, 4th Edition, 2002, 4, 37-53.

26. J. H. Meurman,. Siikala1, M. Richardson and R. Rautema, Non-Candida albicans Candida yeasts of the oral cavity, Communicating

27. Current Research and Educational Topics and Trends in Applied Microbiology, A. Me'ndez Vilas (Ed.), CFORMATEX 2007

\section{How to cite this article:}

Kirti Nirmal, Swati Nirmal, Rohit Chawla and Baveja, C. P. 2021. Evaluation of HiCrome Candida Differential Agar for Identification of Candida Isolated from Various Clinical Specimens. Int.J.Curr.Microbiol.App.Sci. 10(08): 341-350. doi: https://doi.org/10.20546/ijcmas.2021.1008.041 